\title{
Mindfulness i svenska kontexter
}

\author{
KATARINA PLANK
}

ENGLISH ABSTRACT: Mindfulness can be found in three distinctly different settings in Sweden: therapeutic, commercial and religious. Its greatest expansion can be found within in the Swedish health care system, where mindfulness-based therapies and interventions can be used, and among private operators selling mindfulness courses to both public and private sectors. Here, mindfulness is decontextualised and detraditionalised and presented as a universal life-skill without any religious belonging. Although with a difference: the therapeutic use of mindfulness encourages the individual to delevop metacognition and the ability of decentering, while the commercial use of mindfulness puts greater emphasis to sensory experiences. In the religious context, sati (the Pali term translated into mindfulness) is an integral part of a Buddhist soteriologiskt system aiming at freeing the individual from worldly bonds. This shift in conceptualising mindfulness reflects a general trend in Western countries where spirituality replaces religion.

SVENSK RESUMÉ: Mindfulness återfinns i tre distinkt olika sammanhang i Sverige: terapeutiska, kommersiella och religiösa. Sin största spridning har mindfulness fått $i$ sekulära och nyreligiösa former som återfinns inom svensk sjukvård där mindfulnessbaserade terapier integrerats $i$ behandlingar och hos privata aktörer som säljer mindfulnesskurser till både offentlig och privat sektor. Här har mindfulness avkontextualiserats och presenteras som en allmänmänsklig färdighet utan kopplingar till religion, dock med skillnaden att det terapeutiska användandet tycks syfta till att individen utvecklar decentrering och metakognition, medan det kommersiella användandet $i$ större grad betonar sinnesupplevelser. I religiösa sammanhang utgör sati (palitermen som kommit att översättas med engelskans mindfulness) en integrerad del $i$ ett soteriologiskt system som syftar till att individen frigör sig från världsliga bindningar. Begreppsglidningen reflekterar en generell utveckling $i$ västerländska länder där andlighet ersätter religion. 
KEYWORDS: Mindfulness; Buddhist meditation; vipassana; mindfulness based interventions; health; therapy; Swedish health care system; Buddhism in the West

Mindfulness har blivit en internationellt använd term som i sin anglifierade form syftar på någon slags meditationspraktik som (bland annat) förväntas skapa ökad närvaro i nuet och få människor att må bättre. Mindfulness har sitt ursprung i buddhistiska meditationsmetoder och dess ursprung finns mer specifikt att finna i det theravadabuddhistiska begreppet sati. I buddhistiska sammanhang brukar sati översättas med medvetenhet eller uppmärksamhet, medan förespråkare för de nya mindfulnessterapierna istället talar om medveten närvaro.

Mindfulness är det enskilt viktigaste inslag som har plockats upp från buddhistiska traditioner och som de senaste tio åren kommit att influera olika sekulära sektorer i det svenska samhället, samtidigt som buddhistisk meditation i jämförelse är en tämligen marginaliserad företeelse. Det går att identifiera tre distinkta sammanhang där mindfulness lärs ut i Sverige: religiösa, terapeutiska och kommersiella sammanhang. I religiösa sammanhang utgör buddhistisk meditation en lockelse för främst konvertiter, och det lärs ut med en tydlig religiös förankring - även om användarna inte nödvändigtvis behöver ha en religiös motivation för att lära sig meditationsformerna. Det terapeutiska användandet av mindfulness innefattar olika kontemplativa behandlingsmetoder som utvecklats med ett medicinskt syfte och med en tydlig icke-religiös inramning - det rör sig om sekulära metoder som lärs ut av psykologer, läkare, psykoterapeuter och kuratorer för att komma till rätta med medicinska och psykiska problem. Det kommersiella användandet av mindfulness utmärker sig genom sin ekonomiska komponent (i de religiösa och terapeutiska sammanhangen saknas den ekonomiska vinningen för enskilda meditationslärare, liksom försäljningsaspekten), och här marknadsförs mindfulness ofta av personer som är verksamma inom självhjälpsområdet (som kan uppvisa nyandliga förtecken), där mindfulnessinstruktörer kan fungera som coacher, terapeuter, författare till självhjälpsmanualer eller som kursinstruktörer som riktar sig till såväl offentlig som privat sektor.

Flera forskare, däribland Olendzki (2005) och McMahan (2008), har noterat att buddhistisk meditation har genomgått en stark kulturell anpassning när meditationsmetoderna börjat användas i västerländska länder och blivit en privatiserad, avinstitutionaliserad och avtraditionaliserad sysselsättning, samt hur detta utgör en betydande utveckling i buddhismens västerländska historia.

Artikeln har två syften: 1) att belysa denna utveckling i en svensk kontext och besvara frågorna: Vad kännetecknar mindfulness inom de olika arenorna (de religiösa, terapeutiska och kommersiella sammanhangen)? Vilka lär ut mindfulness? Vilken är deras bakgrund? Vilka är avnämarna? Vad syftar användandet av mindfulness till i de olika kontexterna? 2) att fördjupa diskussionen kring hur mindfulness tolkas inom 
respektive kontext och därigenom tydliggöra hur förändringar i konceptualiseringen av mindfulness möjliggjort dess reception inom nya arenor i Sverige.

Materialet som slutsatserna bygger på innefattar kartläggningar av buddhistiska grupper i Sverige, fältarbete inom theravdabuddhistiska meditationsgrupper, textstudier av vetenskapliga artiklar som diskuterar mindfulnessbaserade terapiformer samt böcker skrivna av svenska mindfulnessförespråkare. ${ }^{1}$

Artikeln diskuterar först de terapeutiska och kommersiella arenorna för mindfulness, för att slutligen kontrastera dessa tolkningar med hur sati förstås och tillämpas i buddhistiska religiösa sammanhang.

\section{Terapeutiska arenor för mindfulness}

På olika vårdcentraler ${ }^{2}$ runt om i Sverige, liksom i vissa landstings regi, har patienter börjat erbjudas möjligheten att delta i mindfulnessbaserade gruppbehandlingar. ${ }^{3}$ Vanligtvis är det legitimerade psykologer med en kognitiv beteendevetenskaplig bakgrund som kompletterar sina psykologiska behandlingar med mindfulnessprogram som ett led i vårdgivande verksamhet. Mindfulnesstekniker används även och i större utsträckning än gruppbehandlingar - av många kbt-terapeuter i individualterapi.

Kognitivt betendeinriktade terapier, KBT, har haft en tämligen långsam utveckling i Sverige, jämfört med länder som USA, Kanada, Storbritannien och Australien där kognitiv beteendeterapi har ett starkt fäste bland psykologer, psykoterapeuter och andra som arbetar inom psykiatrisk vård. Detta håller nu att förändras i Sverige, och KBT är på frammarsch. Socialstyrelsen har i sina nya nationella riktlinjer angett att KBT är den första rekommenderade behandlingen, till och med före medicinsk behandling, av många depressions- och ångesttillstånd. ${ }^{4}$ Detta har lett till att efterfrågan är större än utbudet, och vissa landsting saknar terapeuter med KBTkompetens. De kan därför inte erbjuda specialistvård. ${ }^{5}$ Bland de KBT-terapeuter som är verksamma vid landstingen, torde användandet av mindfulnessbaserade tekniker vara stort, både i individuell terapi och i gruppterapi. En av anledningarna till detta är att det är möjligt att i KBT-utbildningen ersätta en stor del av terapeutens egenterapi med mindfulness, till exempel genom en instruktörskurs i MBSR, Mindfulness

För en utförligare genomgång av materialet, se Plank (2011). Artiklen är en omarbetad version av kapitel 7 “Mindfulness - religiösa och terapeutiska funktioner av buddhistisk meditation" i Plank 2011.

En vårdcentral är en vårdenhet med mottagningsverksamhet inom landstingets primärvård för hälsooch sjukvård där flera vårdaktiviteter ges (som exemplevis läkarvård, sjuksköterskemottagning, psykologmottagning, barnhälsovård, mödravård).

En sökning på Google.se och sökorden "mindfulness" samt "vårdcentral” indikerar att detta förekommer från söder till norr vid vårdcentraler som Värmdö, Ronneby, Sotenäs, Västerås, Sävsjö, Norsborg, Ytterby, Bålsta. [Sökning utförd 2012-03-02]

4 Nationella riktlinjer för vård vid depression och ångestsyndrom 2010 - stöd för styrning och ledning, Socialstyrelsen, 2010.

http://www.kbt.nu/kbtinfo/historiskt.asp?sida=historiskt (accessed 2010-09-14). 
Based Stress Reduction, eller MBCT, Mindfulness Based Cognitive Therapy (se Plank 2010).

Den vanligaste mindfulnessbaserade interventionen är ett MBSR-progam (Mindfulness Based Stress Reduction) som sträcker sig över åtta till tio veckor. MBSR är utvecklad i en beteendemedicinsk miljö för patienter med kronisk smärta och stressrelaterade sjukdomar, och lärs ut i en grupp om cirka 30 personer som träffas en gång i veckan under cirka 2-2,5 timmar. Under mötena ges instruktioner och övningar som kompletteras med diskussioner om stress och coping-stategier. Deltagarna får hemläxor där de uppmanas att öva varje dag. Flera mindfulnessövningar/meditationer lärs ut: liggande kroppsskanning med slutna ögon; sittande meditation med uppmärksamhet på andetaget samt uppmärksamhet på förnimmelser; hatha-yoga övningar med mjuka rörelser och stretching; samt att lära sig vara medvetet närvarande i vardagliga aktiviteter som gående, ätande, stående (Baer 2003, 126).

Kabat-Zinns program nådde snabbt framgång eftersom det innehöll specificerade tekniker (en manualiserad form av mindfulnesspraktik) som kunde ligga till grund för välkontrollerade studier som utvärderar effekten av mindfulness på ett vetenskapligt sätt, och som sedan kunde upprepas av andra. Resultaten för MBSR i randomiserade, kontrollerade studier har varit lovande (Åsberg et al 2006), vilket är en anledning till att psykologer och forskare använt sig av mindfulness i utvecklandet av andra metoder. Teasdale, Segal och Williams har t.ex. använt och anpassat mindfulness i sitt MBCT Mindfulness Based Cognitive Therapy, för att behandla patienter som haft fler än tre depressioner (Dryden \& Still 2006).

Inom landstingens regi kan patienterna även erbjudas kurser i MBCT, Mindfulness Based Cognitive Therapy, och DBT, Dialectical Behavior Therapy. MBCT är utvecklat för att förhindra en eskalering av negativa tankar och på så sätt förhindra återkommande depressioner. Det är också en manualbaserad gruppbehandling som lärs ut under 8 veckor. Till stora delar är det baserat på MBSR, men med skillnaden att MBCT tar in element av kognitiv terapi för att underlätta ett decentrerat förhållningssätt till tankar, känslor och kroppsliga upplevelser (Baer 2003, 127). DBT, dialektisk beteendeterapi, syftade ursprungligen till att hjälpa personer med emotionell instabil personlighetsstörning att bättre hantera sina känslor, och har kommit att användas även på andra problemområden som ätstörningar, drogmissbruk, depression och aggressions- och misshandelsproblematik. DBTs terapiprogram kan pågå under flera års tid, och inkluderar gruppträffar varje vecka samt individuella möten med en personlig terapeut. Terapin utgår ifrån en dialektisk världsbild, som postulerar att verkligheten består av motsatta krafter. Den centrala dialektiken utgörs av spänningsfältet mellan förändring och acceptans, där mindfulness lärs ut i syfte att förena dessa aspekter. DBTs behandlingsprogram innehåller ett brett urval av kognitiva och beteendemässiga interventioner som syftar till att förändra tankar, känslor och beteenden hos deltagarna. Behandlingsformen föreskriver inte någon specifi- 
cerad frekvens eller längd för meditation. Terapins utvecklare, Marsha Linehan, har noterat att vissa patienter är ovilliga eller oförmögna att meditera i den utsträckning som MBSRs program föreskriver. Istället sätter patienten upp individuella mål i samråd med sin terapeut. I färdighetsträningsmanualen till DBT finns mindfulnessövningar som anpassats efter den vietnamesiske meditationsläraren Thich Nhat Hanh. Terapeuterna uppmuntras även att pragmatiskt anpassa övningarna till patienternas behov och förmåga såväl som sina egna. Ibland kan det röra sig om regelrätta meditationsövningar, ibland visualiseringar. Linehan omnämner olika mindfulnessfärdigheter som patienten strävar efter att utveckla: tre "vad"-förmågor som rör observation, beskrivning och deltagande, samt tre "hur"-förmågor som rör ickedömande, fokuserat och effektivt (Baer 2003, 127).

Utöver dessa mindfulnessterapier och -interventioner finns även ACT, Acceptance and Commitment Therapy, samt RP, Relapse Prevention (återfallsprevention). Inom ACT återfinns flera strategier som är i enlighet med vad övriga mindfulness-terapeuter förespråkar, nämligen att patienten strävar efter att överge sina försök att kontrollera sina känslor och tankar för att istället observera utan bedömning och därmed acceptera dem genom att se verkligheten som den är. Därigenom kan patienten nå ett förändrat beteende som också förbättrar hennes liv (Baer 2003, 128). Återfallsprevention, RP, är en KBT-behandling som syftar till att förebygga återfall bland de som behandlats för substansmissbruk. Inom RP används mindfulness som en förmåga som involverar acceptens av de ständigt förändrande erfarenheterna i nuet. Patienten lär sig att surfa på den våg av begär som sätter in, utan att behöva ge efter för suget (Baer 2003:128). En vidareutveckling av RP, där mindfulnessinslagen betonas än mer, har resulterat i MBRP Mindfulness Based Relapse Prevention (Bowen, Chawla \& Marlatt 2011).

Det är vanligt idag att alla dessa terapier och interventioner refereras till som "mindfulness-based approaches", metoder eller tillvägagångssätt som är baserade på mindfulness (Chiesa \& Malinowski 2011).

Flera svenska läkare har bidragit till att väcka intresse för mindfulnessbaserade terapier och gjort dem tillgängliga inom svensk sjukvård (se exempelvis Kåver 2004, Nilsonne 2004, Schenström 2007).

Begreppet mindfulness slog igenom år 1990 när molekylärbiologen Jon KabatZinn's bok Full Catastrophe Living publicerades. Kabat-Zinn hade under flera års tid själv gått i lära och hämtat inspiration hos buddhistiska lärare, främst västerländska vipassana-lärare som Goldstein och Korfield, men även zenmästaren Thich Nhat Hahn, och han sökte sedan isolera en teknik, mindfulness, från sin kontext i buddhistisk praktik.

Det råder ännu inte någon överenskommelse kring hur mindfulness konceptualiseras, och det finns ett behov av att nå tydlighet kring vad som åsyftas (Brown, Ryan \& Creswell 2007, 215). Olika författare lyfter fram aspekter som: en självreglerande kapacitet, en accepterande förmåga, en metakognitiv förmåga. Emellertid utgår flera 
av de terapeutiska tolkningarna oftast från Jon Kabat-Zinns definition, där mindfulness översätts med "medveten närvaro": "Medveten närvaro innebär en alldeles särskild sorts uppmärksamhet som är avsiktlig, opartisk och riktad mot nuet." (KabatZinn 2005, 22).

När mindfulness diskuteras brukar tre element återfinnas: “(1) awareness, (2) of the present experience, (3) with acceptance" (Germer 2005, 7). Med acceptans menar Germer att det finns en vilja att låta saker och ting vara som de är vid det tillfälle som de uppmärksammas, genom att acceptera njutbara och smärtsamma upplevelser när de uppstår (Germer 2005, 7). Acceptans är ett centralt begrepp i den pågående nutida diskussionen inom psykoterapin, och Bear (som forskar kring DBT) menar att mindfulness kan utgöra en metod för att lära ut denna färdighet (Baer 2003, 130). Hon framhåller att till skillnad från kognitiv terapi, inkluderar mindfulness inte en evaluering av tankar som rationella eller förvrängda, och inte heller innehåller mindfulnesstreapierna ${ }^{6}$ försök till att förändra tankar som bedömts som irrationella. Istället uppmanas patienten att notera deras föränderlighet, och att avstå från att evaluera dem. Traditionell kognitiv terapi har också tydliga mål (ett förändrat beteende eller tankemönster). I kontrast förmedlar mindfulness en till synes paradoxal attityd av icke-strävan (Baer 2003, 130).

De specifika kliniska tillvägagångssätt som forskarna och behandlare har arbetat med, har kommit att färga av sig på definitionerna och de begrepp och åsyftanden som kopplats till mindfulness. Kabat-Zinn söker beskriva träningen i MBSR, och Baer de färdigheter som uppövas i DBT. Brown, Ryan och Creswell $(2007,215)$ påpekar att när klinikerna och forskarna begreppsliggör mindfulness, sker det just utifrån mindfulness-relevanta praktiker och de förmågor som man syftar till att träna genom mindfulnessinterventionerna. Brown, Ryan och Creswell invänder mot detta, och betonar att mindfulness är en kvalité i medvetandet som manifesteras i de aktiviteter som används för att berika denna kvalité - men som inte korresponderar med aktiviteterna $(2007,215)$.

\section{Kommersiella arenor för mindfulness}

Mindfulness har de senaste åren även kommit att marknadsföras som en form av personlig utveckling och som ett stressreducerande verktyg. Mindfulnesskurser har därför börjat saluföras av mindfulness-coacher och -instruktörer, yogalärare och

6 Baer menar att mindfulness-terapierna innehåller fem delar som tillsammans bidrar till att hjälpa patienten: 1) Exponering av obehagliga känslor: när individen tränas i att uppleva exempelvis smärta eller ångest utan att reagera känslomässigt på detta, anses detta leda till desensitivering, det vill säga att över tid blir reaktionen mindre uttalad. Detta kan hjälpa både vid kronisk smärta och vid emotionellt instabil personlighetsstörning. 2) Kognitiv förändring: attityder till tankar och förändring i tankemönster. 3) Självobservation: leder till att identifiera fler coping-strategier. 4) Avslappning 5) Acceptens: alla behandlingsformerna innefattar acceptens av smärta, tankar, behov, andra kroppsliga, kognitiva och emotionella fenomen utan att individen försöker förändra, smita ifrån eller undvika dem (Baer 2003, 130). 
hälsogårdar som riktar sig till privatpersoner, liksom av olika företag som riktar sig till offentliga sektorn, skolan samt näringsliv för att sälja personalutvecklande kurser. Marknadsföringen av mindfulness som riktar sig till arbetsgivare betonar ofta hur individen kan bli en bättre medarbetare eller ledare, som på denna hemsida som säljer kurser i mindfulness för ledare:

Ledare av idag har kravet på sig att vara flexibla och lyhörda. För att bli mer anpassningsbar i sitt ledarskap behöver man se bortom sina gränser, öppna upp för nya sätt att lyssna, leda och bemöta. Man måste utvecklas. Genom mindfulnessträning förbättrar individen sin uppmärksamhet och medvetenhet vilket ger mer inspiration, öppenhet och balans. Endast när vi helt och fullt är närvarande i ögonblicket, i nuet är det möjligt att: bli medveten om och stoppa sin autopilot; se sig själv och andra klart och tydligt; lyssna och vara närvarande i nuet; ha större engagemang i komplexa och känslomässiga förändringsprocesser; öka balansen och motståndskraften hos de anställda och deras liv. ${ }^{7}$

Gemensamt för dessa kommersialiserade mindfulnesskurser är att de faller inom ett spektrum som kan benämnas nyandlighet där religiositet uttrycks i hälsomässiga aspekter och med en betoning på att utveckla individens inre potential. Denna form av mindfulness uppvisar starka likheter med den nyandliga sektorn där coaching och "terapi" kan ses som nya rituella praktiker i det senmoderna Sverige (Hornborg 2012, 2010a, 2010b). Inom fältet spirituell terapi ser Hornborg fem gemensamma nämnare: 1) självutnämnda ledare, dvs att lärarna/ledarna oftast saknar kvalificerade utbildningar inom sitt område, och har istället genomgått olika kurser som leder till “diplomering", "certifiering", "auktorisering" 2) individcentrerade riter, 3) förverkligande av Självet, 4) intensiva känslor, och 5) profit.

Många av mindfulnessinstruktörerna, coacherna mm kan betecknas som egencertifierade lekmän och lekkvinnor. De har fått sina utbildningar hos organisationer inom den egna branschen, som inte ingår i myndigheternas utbildnings- eller granskningssystem. Den blivande instruktören behöver sällan ha egen långvarig meditativ erfarenhet. Istället är det är vanligt att mindfulness-instruktörer eller coacher har fått sin träning från kurser som influerats av MBSR, där mindfulness presenteras som en life-skill, en skicklighet som ska berika individens liv genom att fokusera på nuet och genom att uppskatta och förnimma en ökad sinnlighet. Inom de kommersiella arenorna säljer dessa självutnämnda ledare mindfulness till olika målgrupper. Många kurser riktar sig även till privatpersoner, där mindfulness förs in som en aspekt som berikar det vardagliga livet. Det är inte ovanligt att marknadsföringen även riktar sig till olika samhälleliga instanser, som skolans värld eller till sjukvårdens chefer.

Ett segment av den kommersiella sektorn leds emellertid av välutbildade personer som tidigare har arbetat, eller som fortfarande arbetar, inom sjukvården. Deras

${ }^{7}$ http://www.humanpro.nu/ledarutveckling/ledarskap-och-mindfulness-2610708 [accessed 2012-03-12]. 
kurser riktas ofta till anställda inom vården, och till forskare som ägnar sig åt klinisk forskning. Flera av dessa har som ambition att påverka vården genom att föra fram förmänskligande ideal, och på så sätt bidra till en positiv mänsklig och samhällelig utveckling.

Mindfulness i kommersiell tappning tar också sin utgångspunkt i Kabat-Zinns betoning av medveten närvaro, men till skillnad från det terapeutiska användandet av mindfulness som tycks syfta till decentrering och utvecklandet av metakognition (där en distansering sker mellan den som upplever och det upplevda) betonas i den kommersiella tolkningen istället en stark uppskattning av sinnlighet. En mindfulnesslärare som håller kurser i mindfulness och födande får exemplifiera denna tolkning av mindfulness som en förstärkning av sinnestryck:

För mig är det magiska med mindfulness att det gör det möjligt att se och uppleva det lilla i livet - se träden vaja i vinden, känna solens strålar mot min hud, njuta av skrattet från min busiga 2-åring som precis blött ner hela badrummet - som egentligen är det stora i livet. Med två små barn och allt annat som pockar på i vardagen så hjälper mindfulnessutövandet mig att uppleva ögonblicket istället för att bara se det som måste göras i form av tvätt, matlagning och allt det där andra. ${ }^{8}$

När mindfulness presenteras i kommersiella sammanhang sker detta i en rituell kontext som betonar individen och självet, och där hälsomässiga fördelar lyfts fram. Här är mindfulness även förbundet med starka ekonomiska krafter; att vara mindfulnessinstruktör kan bli till ett yrke, där instruktörens försörjning kan vara avhängig antalet kurser som säljs. Kommersialiseringen av mindfulness präglas dessutom implicit av kravet att kursen ska "leverera" resultat - att köparen/konsumenten får direkt utdelning på sin investering.

\section{Religiösa arenor för mindfulness}

Under en retreat, anordnad av den buddhistiska meditationsgruppen Vipassanagruppen, lär den amerikanske munken Bhante Rahula ut insiktsmeditation, vipassana, till ett trettiotal meditatörer. Varje dag under kursen reciterar munken två verser, nr 21 och 22, ur Dhammapada. Recitationen görs på pali, och sedan översätter han stroferna: "Hellre än att leva hundra år, med odisciplinerat sinne och utan meditation, är det bättre att leva en enda dag med god disciplin och meditation. Hellre än att leva hundra år utan att se hur ting uppkommer och försvinner, är det bättre att leva en enda dag och se denna process. Mindfulness är vägen till frihet från döden (nibbana), medan ett sinne utan mindfulness fortsätter att vara underkastad döden. Den som är mindful, dör inte, medan den som inte är mindful lever som vore den död. En vis person dväljer i mindfulness, och njuter av en lycksalighet bortom födel-

$8 \quad$ http://www.mindfulgravid.se/lararna.html [access 2012-03-12] 
se och död." Genom att knyta an till Dhammapadas kärnfulla strofer, påminner Bhante Rahula mediatörerna om att mindfulness och insiktsmeditation syftar till att utveckla en djup visdom som ska användas för att se igenom tillvarons förgänglighet och hur en oförmåga att se detta leder till ett sinne som präglas av de ogynnsamma rötterna (mula): okunskap, begär och hat. Inom theravadatraditionen anses dessa tre rötter som orenheter, och rötterna utgör de grundläggande drivkrafter som leder en individen till fortsatta återfödelser. Endast genom att förstå orenheterna med djup visdom, utvecklad i insiktsmeditation, kan individen uppleva ett seismiskt skifte i medvetandet som frigör henne från bundenheten till världen, och därigenom kan hon uppleva en frihet från döden.

Inom de buddhistiska traditionerna existerar inte något begrepp som motsvarar termen meditation, istället används pali/sanskrit-begreppet bhavana, som betyder ungefär mental kultivering - att odla eller rena sinnet. Inom theravada-traditionen innefattar denna mentala kultur en process i tre steg, som anses så sammanbundna och beroende av varandra att de måste utvecklas samtidigt, för att sinnet ska kunna tränas. Sila, moralen, att leva efter de fem precepten att inte döda, ljuga, stjäla, missbruka sin sexualitet eller berusa sig, ligger till grund för samadhi, koncentrationen, som i sin tur är en förutsättning för att panna, visdom, ska kunna utvecklas. Träningen av sinnet sträcker sig alltså över ett mycket bredare fält än vad vi oftast asscocierar till begreppet meditation - en slags koncentrativ teknik - och innefattar individens livsföring. När individen är uppmärksam på sitt beteende och disciplinerar sitt yttre handlande, innefattar denna uppmärksamhet ofta (åtminstone i idealfallen för meditatörer) samtidigt en medvetenhet om inre impulser och mentala sinnestillstånd.

I buddhistiska kontexter återfinns mindfulness främst inom theravadatraditionen, där termen blivit den etablerade engelska översättningen av termen sati. På svenska brukar sati istället översättas med "rätt medvetenhet" (Johansson 1983, 31) eller "rätt uppmärksamhet" (Jacobsen 2002, 105). Sati utgör här en central del i insiktsmeditation, vipassana. Vipassana har kommit att bli en samlingsbeteckning för flera olika meditationsmetoder inom theravada-traditionen som alla syftar till att den praktiserande individen ska utveckla en erfarenhetsbaserad kunskap om förgänglighet och därigenom nå befriande insikt. ${ }^{9}$

9 Paliordet vipassana har flera olika betydelser. Det syftar dels på den klargörande blixt av befriande intuitiv kunskap som anses markera kulmen på theravadabuddhistisk meditationspraktik (Nyanatiloka 1997); dels på sinnets förmåga att tydligt bevittna hur händelseförlopp utvecklas i det pågående nuet och är på så sätt en skicklighet som meditatören utvecklar genom olika meditativa redskap och tekniker och som för meditatören till tröskeln där den befriande insikten nås (Thanissaro 1997); dels på ett meditationssystem som oftast kallas vipassana-meditation (ibland skrivet med kapitält V) eller insiktsmeditation som grundar sig på tolkningar av Satipatthana Sutta. Som meditationssystem eller meditationspraktik är vipassana synonymt med satipatthana och kammathana. Satipatthana refererar till hur medvetenhet, sati, etableras (se kapitel sju) och kammathana, som betyder"arbetsbasen" för meditation och är ett begrepp som är allmänt förekommande i Burma, syftar på att man använder något av de fyrtio meditationsobjekt som beskrivs i den omfattande meditationsmanualen Visuddhimagga ("Vägen till renhet"). 
Det finns även mahayanabuddhistsika grupper som på senare år kommit att lyfta fram sin praktik som mindfulness, som exempelvis tibetanska buddhistiska grupper och Triratana/Västerländska buddhistordens vänner. Gruppernas presentation av sin verksamhet har således påverkats av hur mindfulness som begrepp kommit i ropet de senaste tio åren. ${ }^{10}$

Antalet buddhister i Sverige omfattar ungefär 30000 människor med asiatiskt ursprung och några tusentals konvertiter (Plank 2011). Eftersom majoriteten av de som utöver vipassana är konvertiter, handlar det kanske om några tusentals personer som fått undervisning i buddhistisk mindfulness (sati). Det är svårt att göra mer precisa skattningar, då religionstillhörighet inte registreras i Sverige och det även saknas en kartläggning av utbredningen av mindfulness.

Undervisning i sati och vipassana sker vanligtvis under retreat, under kurser om sju till tio dagar, eller under veckovisa möten i tempel eller i föreningslokaler. Meditationsundervisning är dana-baserad, vilket innebär att lärarna (både munklärare och lekmannalärare) ger sin undervisning helt utan kostnad, och där deltagarna är fria att lämna en gåva efter sin förmåga och om de önskar. Dana-principen är central, eftersom meditationsundervisningen och den buddhistiska läran anses vara en så dyrbar gåva att den är oersättlig. Det är buddhistisk kutym att den alltid ska ges fritt. Däremot kan man för att täcka omkostnader för hyra, logi och kost finansiera detta genom antingen kursavgifter eller medlemsavgifter.

I den theravadabuddhistiska traditionen förstås sati som en viktig del för att individen ska kunna nå den slutliga befrielsen (nibbana). Sati placeras i en soteriologisk referensram, där sati är en av fem andliga styrkor (bala) att träna sig i, liksom sati är den första av de sju faktorer (bhojjanga) som leder till uppvaknande. Dessutom utgör sati den sjunde länken i den åttafaldiga vägen (magga). Den åttafaldiga vägen inkluderar tre områden som ska utvecklas parallellt för att nå uppvaknande: en etisk livsföring, en träning i koncentration och utvecklandet av visdom. Här ses sati således som en del av en etisk hållning som är nödvändig för att utvecklas andligen. Om den etiska referensramen saknas kan sati inte definieras som samma sati "rätt sati" som den åttafaldiga vägen stipulerar, istället definieras uppmärksamheten som micca sati, fel sorts sati. På svenska översätts samma sati antingen till "rätt medvetenhet" (Johansson 1983, 31), eller "rätt uppmärksamhet" (Jacobsen 2002, 105). Rätt sorts sati kan genereras när en individ utför karmiskt gynnsamma handlingar, eller handlingar som är förknippade med högre och renare medvetandetillstånd. Giplin $(2008,228)$ understryker att "rätt sati" (samma sati), som omnämns i den åttafaldiga vägen, bara kan uppstå i sobhana-citta, en Abhidhammaterm som syftar på ett medvetande som är karmiskt gynnsamt (kusala) eller som innefattar dess gynnsamma resultat (kusala-

10 När jag gjorde min första kartläggning av buddhistiska grupper i Sverige som genomfördes 2002-2003 (se Plank 2005) användes inte mindfulness-termen av tibetanska grupper eller av VBV för att marknadsföra meditationskurser. Mindfulness-terapierna hade heller inte fått genomslag. När jag reviderade artikeln (se Plank 2009) hade däremot trenden blivit tydlig och jag inkluderade ett stycke om mindfulness i vården. 
vipaka). Det moraliska kriteriet som avgör vad som är gynnsamt bygger på om sinnet och intentionen i handlandet styrs av närvaron eller frånvaron av de tre "rötterna" (mula): sinnet måste vara fritt från begär, fritt från aversion och fritt från okunnighet (alobha, adosa och amoha), för att en handling ska vara gynnsam. ${ }^{11}$ Låt mig förtydliga detta med ett konkret och vardagligt exempel: om jag river sönder ett papper i ilska anses denna handling vara karmiskt ogynnsam. Även om mitt handlande inte får konsekvenser för någon annan människa eller varelse, genererar det ogynnsam karma, eftersom själva intentionen i mitt agerande är präglat av aversion, till skillnad från om jag delar pappret itu bara för att det behöver göras och utan att kroppen och sinnet är färgat av emotioner. Karma är således en religiös lagbundenhet, som visar på hur individen närmar sig eller distanserar sig från det yttersta målet, nibbana. ${ }^{12}$

De ogynnsamma rötterna kan manifestera sig mycket subtilt, i form av de fem hindren, (nivarana). Det innebär att alla de tillstånd som är förknippade med sinnesnjutningar, irritation eller ilska, trötthet och lojhet, rastlöshet och oro samt skeptiska tankar, medverkar till att skapa en ogynnsam intention om man agerar utifrån dem i tanke, tal eller kroppslig handling. Thanissaro Bhikku (2010b) påpekar därför att etablerandet av sati (här nedan översatt med mindfulness, vilket är den gängse engelska översättningen av sati) inte enbart handlar om att acceptera olika sinnestillstånd, utan lika mycket att se och förstå dem, för att kunna ersätta dessa negativa tillstånd med mer gynnsamma: ${ }^{13}$

[I]n establishing mindfulness you stay with unpleasant things not just to accept them but to watch and understand them. Once you've clearly seen that a particular quality like aversion or lust is harmful for the mind, you can't stay patient or equanimous about

11 Det är själva intentionen i handlingen som anses vara avgörande för de karmiska konsekvenserna. Handlingar omfattar individens tankar, tal och kroppsliga uttryck. Styrs intentionen av ett sinne som är präglat av begär, aversion eller okunnnighet leder det till akusala, ogynnsam, kamma. Styrs intentionen av ett sinne som är fritt från de tre orenheterna, uppstår kusala, gynnsam, karma.

12 Karma är en religiös lag som är värderande; det finns vissa saker som anses vara bra, goda, gynnsamma och som i kraft av detta även ger gynnsam frukt (vipaka) det vill säga ett gynnsamt resultat. Och vissa saker som anses vara fel, dåliga, ogynsamma och därför leder till ogynnsam frukt. (En handling ses alltså inte som rätt eller fel för att den leder till ett gott eller dåligt resultat. Handlingen leder till ett gott eller dåligt resultat därför att den är rätt eller fel.). Det finns dessutom tydliga kriterier som avgör om en handling är karmiskt gynnsam eller ogynnsam: dess motiverande rot (intention), den lycka/olycka handlingen bringar en själv och andra samt i vilken utsträckning den bidrar till andlig utveckling (eller dess motsats).

13 Gynnsamma mentala tillstånd är sati, metta (kärleksfull godhet), icke-begär, visdom/klar förståelse av hur saker är, frid, tillfredsställelse med det som är enkelt och gott, en vilja att känna till och agera utifrån sanning, och en glädje i andras glädje. Ogynnsamma mentala tillstånd är kopplade till de fem hindren. Depression, melankoli, tröghet och distraktioner är till exempel akusala (ogynnsamma) mentala tillstånd, men i vårt (svenska) språkbruk skulle de inte kategoriseras som onda eller omoraliska. De fem hindren, nivarana, definierade av Nyanatiloka (1997), är: 1. Lustfyllt begär - allt från subtilt gillande till kraftful lust vad gäller behagliga former, ljud, lukter, smaker och känsloytor (kamachanda). 2. Avståndstagande, ovilja - riktar sig mot motbjudande personer eller ting, och kan variera mellan mild förtret till övermäktigt hat (byapada). 3. Slöhet, dovhet, inaktivitet eller mental stelhet, samt bedövning, lojhet eller sömnighet (thina och middha). 4. Rastlöshet och oro, som uppspelthet, agitation eller oförmåga till lugn samt oro utifrån skuldkänslor av att ha gjort moraliska övertramp (uddhacca och kukkucca). 5. Misstro, tvivel, som innebär osäkerhet i fråga om Buddhan, dhamma, sangha och träningen (vicikiccha). 
it. You have to make whatever effort is needed to get rid of it and to nourish skillful qualities in its place by bringing in other factors of the path: right resolve and right effort (Thanissaro Bhikkhu 2010b).

Till skillnad från hur mindfulness framställs i kommersiella sammanhang som ett sinnestillstånd av "medveten närvaro", innefattar sati i theravadabuddhistiska en funktion i medvetandet, en vaksamhet som möjliggör för individen att observera olika reaktionsmönster och samtidigt balansera mellan olika etiska valmöjligheter. Denna observationsförmåga tycks vara något som även det terapeutiska användandet av mindfulness syftar till, men i den terapeutiska kontexten saknas anknytning till såväl ett etiskt som religiöst system.

\section{Diskussion}

Sati har kommit att ses som kärnan i buddhistisk meditation, och har av sekulära och nyreligiösa företrädare fått en annan innebörd än vad som lärs ut inom theravadatraditionen varifrån begreppet härrör. Därigenom har mindfulness och delar av buddhistisk psykologi genomgått en stark kulturell anpassning (Olendzki 2005, 261). McMahan $(2008,185)$ påpekar att meditation och mindfulness, mer än något annat drag i buddhismen, presenteras som en psykologisk, andlig, eller vetenskaplig teknik snarare än som religiös praktik.

Denna terapeutiska och nyreligiösa trend har medfört att mindfulness letat sig in i den svenska sjukvården, och därifrån ut till kommersiella arenor. Här kan två tydliga användningsområden skönjas: 1) i det (främst KBT-baserade) kliniska användandet av mindfulnessbaserade terapier används MBCT och DBT för att behandla depression och patienter som diagnosticerats med emotionellt instabil personlighetsstörning. Där används även MBSR i medicinskt syfte att behandla bland annat smärta, tinnitus och insomni. 2) Därtill märks en ökande trend där mindfulness presenteras som en "life skill", en slags generell skicklighet som kan användas av alla professioner för att öka sin arbetskapacitet, för att handskas med stress, för att förbättra sina relationer till patienter, kollegor, vänner eller familj. Inom båda dessa användningsområden har läkare och psykologer varit betydelsefulla för att introducera och sprida teknikerna både i Sverige och utomlands (se Plank 2010).

Denna utveckling avspeglar en samtida förändringsprocess inom religion och religiositet i västerländska länder, där religion förknippas med bundenhet till traditionella religiösa system med tydliga dogmer och auktoriteter som ges tolkningsföreträde, medan andlighet och inre upplevelser kommit att värderas högre och står som kontrast till religion (Frisk 2003, 3). McMahan tydliggör hur meditation har blivit privatiserad, avinstitutionalisead och avtraditionaliserad och att detta utgör en betydande utveckling i buddhismens västerländska historia: 
If psychoanalysis has aided in the demythologization of Buddhism, recent practical psychotherapies have helped to detraditionalize it, allowing meditation to operate in non-Buddhist therapeutic settings, often for non-Buddhist goals and without requiring commitment to explicitly Buddhist values. Rather than an integral part of monastic life bound up with its rituals, ethics, and cosmology, meditation has become something not only for lay Buddhists but for all those of any religion or none. The goals of Buddhistinfluenced psychotherapy are usually stated in terms of western psychotherapeutic tradition: alleviation of symptoms, overcoming of depression, mitigation of obsessive thoughts, integration of the person, self-realization, and so on. Often Buddhism serves as a reservoir of techniques that might be useful to accomplish such extra-Buddhist goals. Psychotherapy is one of the most visible arenas where Buddhism is transforming around the edges, as it were - where Buddhism blends into non-Buddhism (McMahan $2008,57)$.

Det tycks som meditationsutövning passar särskilt väl in i det "terapeutiska ethos" som sociologen James L. Nolan (1998) identifierat och menar dominerar framför allt amerikansk kultur sedan 1960-talet. Det terapeutiska ethoset har tre kännetecknande drag: 1) självet uppskattas, aktualiseras, bekräftas och ska vara obundet, 2) de personliga känslorna står i centrum som huvudsaklig källa till kunskap och auktoritet, vilket lett till 3) en formell institutionalisering av ett nytt slags prästerskap av kliniskt verksamma psykologer, kuratorer, psykiatriker och andra rådgivare och terapeuter har kunnat etablera sig (Nolan citerad i Lasch-Quinn 2004, 5). Liselotte Frisk lyfter fram ytterligare sex drag som kännetecknar skiftet från religion till andlighet i Sverige: 1) från partikularism till eklekticism, 2) från dogma till upplevelse, 3) från det kollektiva till det personliga, 4) från hierarki till jämlikhet, 5) från Gud till människa, 6) från en betoning på vad som händer efter döden till inomvärldslighet (Frisk 2006).

Ett distinkt drag i det nutida användandet av (buddhistisk) meditation - inte bara bland västerländska konvertiter utan även bland asiater - är att det anses vara en avtraditionaliserad from av meditation (McMahan 2008). Ett av de tydligaste dragen av avtraditionalism, är att individen inte längre är bunden i tid och rum till sin omedelbara omgivning, och att hon därför inte längre är "inbäddad" i sin religiösa tradition. Detta har lett till ett auktoritetsskifte från externa till interna källor (Heelas 1996a, 2). I stället för att använda sig av yttre auktoriteter i form av en religiös tradition och dess tolkningstraditioner för att förstå sin religiösa utövning, internaliserar individen sin religiositet och uttolkar den utifrån sina egna individuella förutsättningar och preferenser. Heelas kallar detta för "self-spirituality". Detta har implikationer för hur användare av meditation relaterar till tolkningar och utövandet av meditation - och det går att notera att de med religiös läggning uppvisar både traditionella och avtraditionaliserade drag.

Det tycks som en stor del av de som använder sig av buddhistisk meditation, ger uttryck för senmoderna eller postmoderna sätt att relatera till religion, där individen är sin egen auktoritet. Deltagande i retreat där insiktsmeditation lärs ut kan motive- 
ras av medicinska skäl, psykologiska orsaker, sökandet efter andlighet och i vissa fall ett mer uttalat buddhistisk sökande. I min undersökning av Goenka-rörelsen i Sverige, som lär ut vipassana-meditation, visar det sig att majoriteten av de som kommer till Goenka-kurser kan sägas relatera till rörelsen som "klienter" i Beckfords sociologiska terminologi. Med det menas att de vill ta del av vad som erbjuds, men att de i sina dagliga liv inte nödvändigtvis i någon större utsträckning influeras av rörelsens vision för hur ett liv bör levas, genom att efterfölja de moraliska träningsreglerna, avstå från alkohol, och upprätthållandet av två timmars daglig meditation. Istället blir vipassana en teknik som kan användas och tolkas utifrån individuella smaker, och det finns ett tydligt skifte från organiserad och kollektiv religion till en "selfspirituality". Ungefär tre fjärdedelar av de som deltar i Goenka-kurser kommer inte tillbaka, vilket tyder på att de troligtvis är influerade av ett annan slags religiös orientering där self-spirituality inte innefattar ett åtagande eller en hängivenhet till en enskild tradition. (Plank 2011)

Förutom att det förekommer skillnader i de rituella sammanhang som omger hur sati och mindfulness lärs ut och praktiseras inom de religiösa, terapeutiska och kommersiella arenorna, är mitt intryck att gränserna mellan dessa arenor är tämligen flytande. Människor kan röra sig mellan dessa, och inta olika roller, liksom uppvisa olika grader av deltagande och engagemang. Till exempel kan någon delta i ett buddhistiskt retreat, för att lära sig mindfulness från en munk, och sedan kombinera delar av denna lära och skapa en egen form av mindfulness i sin yrkesutövning som yogalärare eller mindfulnessinstruktör.

\begin{tabular}{|c|c|c|c|c|}
\hline & & \multicolumn{3}{|c|}{ Mindfulness } \\
\hline \multicolumn{2}{|c|}{ Religiös: buddhistisk } & & apeutisk & Nyandlig/kommersiell \\
\hline $\begin{array}{l}\text { Thai, Srilan- } \\
\text { kesisk }\end{array}$ & $\begin{array}{l}\text { Vipassana- } \\
\text { meditation }\end{array}$ & DBT & MBCT & MBSR \\
\hline “inbäddad” & & & & "urbäddad" \\
\hline
\end{tabular}

Tabell 1. Olika sammanhang där sati och mindfulness lärs ut, mer eller mindre inbäddad $i$ buddhistisk tradition.

Den kanske viktigaste förändring som möjliggjort förskjutningen, återfinns i konceptualiseringen av sati, mindfulness. Trots att sati beskrivs och diskuteras ingående av buddhistiska munkar och meditationsmästare inom theravadatraditionen (både $\mathrm{i}$ historiska källor och i nutida utläggningar), har dessa beskrivningar ännu inte översatts på ett koherent sätt i den samtida psykologiska forskningen. Studiet av medvetandet har haft en marginaliserad plats inom den psykologiska vetenskapen, forsk- 
ningen och dess kliniska praktik. Istället intresserar man mest sig för medvetandets innehåll: "Of overwhelming interest to most psychologists is the content of consciousness - thought, memory, emotion, and so on - rather than the context in which those contents are expressed-that is, consciousness itself" (Brown, Ryan \& Creswell 2007, 211). Det är först på senare år som buddhistiska influenser kan märkas inom både psykoterapi och psykologisk forskning, samt inom neoruobiologin. ${ }^{14}$ Den psykologiska forskningen om mindfulness är därför fortfarande i sin linda, och den har hittills fokuserat mer på effekterna av mindfulness, snarare än att förstå betydelsen av och uttrycken för vad mindfulness eller sati är (Brown, Ryan \& Creswell 2007, 211).

Den theravadabuddhistiska förståelsen av sati placerar begreppet i en soteriologisk referensram, där sati är en viktig del att utveckla för att individen ska nå uppvaknande (bodhi) och den slutliga befrielsen (nibbana). ${ }^{15}$ Inom den psykologiska och medicinska forskning som gjorts på mindfulness, har snarare effektiviteten i mindfulnessinterventionerna studerats än själva mindfulnessfaktorn (Christopher et al 2009b). Mycket av mindfulnesslitteraturen är dessutom entusiastisk och okritisk till fenomenet, menar psykologen Robin Åkerlund (2004) i det att den fokuserar på mindfulness som en hälsobringande psykologisk färdighet utan att uppmärksamma att detta inte överensstämmer med buddhistiska traditioners framställning. "Detta aktualiserar frågan om vem som har tolkningsföreträde, inte minst i den mångkulturella kontext som KBT och svensk sjukvård är en del av" (Åkerlund 2004, 54).

Företrädare för mindfulness-terapier är medvetna om att mindfulness i deras användning sker inom områden som skiljer sig avsevärt från sin ursprungliga kontext. Fulton och Siegel framhåller att målet i psykoterapin syftar till att återskapa ett "healthy self", och buddhistisk meditation syftar inte till att "bli någon" utan att nå insikt $\mathrm{i}$ att det inte finns någon bestående princip som kan betecknas som "jag" eller "själv" (det vill säga anatta, icke-själv eller icke-jag). Men idén om icke-jaget är inte främmande för nutida vetenskap, och Fulton och Siegel menar att kontrasterna mellan traditionerna kan framstå som större än vad de egentligen är när de diskuteras konceptuellt än vad som observeras i praktiken (Fulton \& Siegel 2005, 41).

Detta tycks inte psykologerna och meditationsforskarna Roger Walsh och Shauna Shapiro (2006) hålla med om. Istället påpekar de att den generella tendensen inom

14 En nära dialog mellan neorobiologiska forskare och den fjortonde Dalai Lama, tibetanernas högste andlige ledare har utvecklats på senare år. Dalai Lama har kommit att bli en skicklig navigerare som i sina allmänna budskap har lyckats harmoniera, anpassa och omtolka tibetanskbuddhistiska doktriner att vara i samklang med västerländska liberala och demokratiska värden. En sätt har varit att utveckla en dialog med vetenskapen och i synnerhet neurobiologin, vilket buddhismforskaren David Lopez menar är en medveten strategi för att stärka den tibetanska buddhistiska traditionen som befinner sig under kinesiskt förtryck i hemlandet (Lopez 2008, 206-207).

15 Sati är en av fem andliga styrkor (bala) som är viktiga att träna sig i. Sati är även en av den första av de sju faktorer som leder till uppvaknande (bojjhanga), vilket innebär att utan sati kan uppvaknande inte nås. Dessutom utgör sati den sjunde länken i den åttafaldiga vägen (magga), och är en del av den etiska hållning som är nödvändig för att utvecklas andligen. 
meditationsforskningen (som har bedrivits de senaste trettio-fyrtio åren sedan 1970talet) är att den har kantats av betydande missförstånd, och av "assimilativ integration", det vill säga att man har velat anpassa förståelsen av meditation utifrån egna västerländska tolkningar av vad medvetandet är, istället för att se till den rikedom och de unika aspekter som olika meditativa discipliner erbjuder som både psykologier och filosofier. De menar att "there is little appreciation of the major implications that meditation holds for an understanding of such central psychological issues as cognitive and attentional processes, mental training and development, psychological capacities and potentials, health and pathology, and therapeutic and social practices" (Walsh \& Shapiro 2006, 228).

Det som beskrivs som ett nödvändigt försök att isolera ett bärande element ur sitt religiösa och kulturella sammahang, är betydligt mer än så. Det handlar om en process där man även ger meditation nya innebörder, menar de:

Moreover, research findings have been incorporated within Western psychological frameworks ignoring meditation's complementary psychological and philosophical perspective. This has been widely described as a necessary "decontextualization", but it is actually far more. It is also a major recontextualization and revisioning of the practices within an exclusivly Western psychological and philosophical framework (Walsh \& Shapiro 2006, 227-228).

När företrädare för den västerländska psykologin på detta sätt vill sätta agendan och hävda sitt tolkningsföreträde, försvårar man samtidigt för andra psykologier, som den buddhistiska, att nå kredibilitet. Walsh \& Shapiro förordar därför en större lyhördhet både vad gäller kulturell och konceptuell sensitivitet, vilket skulle kunna leda till ett ömsesidigt berikande $(2006,228)$, och de får medhåll från Christophers forskarteam (Christopher et al 2009a, 312).

Bland buddhistiska företrädare märks både försiktighet och en viss kritik av hur mindfulnessbegreppet kommit att presenteras och hur mindfulnessterapierna används. Marie Ericsson, vipassana-lärare från Vipassanagruppen i Stockholm, ser många likheter mellan hur mindfulness inom KBT fungerar med vad vipassanameditation syftar till, men hon ser också var viktiga skillnader finns, nämligen i en disciplinerad moralisk livsföring:

[D]et finns många överensstämmelser, men även skillnader, mellan Buddhas lära och kognitiv terapi. Naturligtvis kan man inte begära att en terapiform samtidigt ska vara en komplett andlig väg. Målet är ju inte detsamma. Men jag tror att en lite större tonvikt både på etik och formell meditation kanske skulle ge ännu mer djup åt terapin. Med etik menar jag att betona att en av förutsättningarna för att må bra, är att man följer de fem träningrreglerna: Att inte döda, stjäla, ljuga eller baktala, samt att inte missbruka droger (inklusive alkohol) eller skada andra med sina sexuella handlingar (Ericsson 2005). 
Även internationellt hörs buddhistiska kritiker som oroar sig över utvecklingen av hur mindfulness framställs. Thanissaro Bhikkhu (2010b) belyser i artikeln “Mindfulness defined", hur mindfulness emellanåt förklaras som en uppskattning av de små njutningar nuet kan erbjuda: smaken av russin, känslan av att hålla en kopp the mellan händerna. Thanissaro påpekar att denna uppskattning, i Buddhans vokabular, kallas för "contentment" och får anses det motsatta till uppvaknande:

Contentment is useful when you are experiencing physical hardship, but it is not always useful in the area of the mind. In fact, the Buddha once said that the secret to his Awakening was that he didn't allow himself to rest content with whatever attainment he had reached. He kept reaching for something higher until there was nowhere higher to reach. So contentment has to know its time and place. Mindfulness, if it's not glommed together with contentment, can help keep that fact in mind (Thanissaro 2010b).

De internationella buddhistiska företrädarna tycks framför allt reagera på att mindfulness framställs som en aktivitet som används för världsliga och inte transcendenta ändamål, samt att det rör sig om grundläggande missförstånd om vad sati är. Med världsligt användande åsyftas framför allt att mindfulness leder till ett bekräftande och cementerande av självet (det vill säga, det saknar det utomvärldsliga målet nibbana), inte att det är lekfolk som använder sig av det i medicinska sammanhang. Det som mindfulness-appropriatörerna beskriver som mindfulness utgör därför i buddhistisk terminologi miccha sati, felaktig sati. Däremot skulle mindfulness i sekulär tappning med lätthet kunna kvalificeras som manasikara, uppmärksamhet. Yoniso manasikara, vis uppmärksamhet, kan vara en synonym till sati, men som vanlig uppmärksamhet, manasikara, behövs uppmärksamheten inte stödjas av vare sig atapi, ihärdighet, eller vineyya abhijjhadomanassa, att vara fri från begär och aversion.

Betoningen på att vara närvarande i nuet ses som essensen av mindfulness i dessa framställningar, och Rapgay \& Bystrisky (2009) menar från buddhistisk synvinkel att man misslyckas med att på ett tillfredsställande sätt särskilja uppmärksamhet och medvetenhet. Uppmärksamhet ses i buddhistisk tolkning som ett medvetandetillstånd, medan medvetenhet är en funktion i medvetandet, och om utövarna inte är på det klara med detta, väcker det frågor om vad de egentligen gör när de utövar mindfulness menar Rapgay \& Bystrisky: "Such questions resonate with traditional practicioners of Buddhist contemplative psychology for whom attention signifies an everchanging factor of consciousness, while awareness refers to a stable and specific state of consciousness. [---] In the process of adaptation, they changed mindfulness from a systematic practice based on a perceptual and cognitive model in Buddhism, to a more general concept of being mindful, i.e. attentive to present moment experience" (2009, 148-149).

Mindfulness i religiösa, terapeutiska och kommersiella sammanhang betyder olika saker, och har olika syften. Kanske kan skillnaden tydligast illustreras med en 
analogi hämtad från Thanissaro (2010a) som förtydligar satis uppgift: i en buddhistisk kontext är uppvaknande att likna vid ett berg i horisonten, och slutdestinationen du kör mot i din bil. Sati är det som påminner om att hålla uppmärksamheten fokuserad på vägen till berget, snarare än att låta uppmärksamheten vara fokuserad på glimtar av berget eller bli distraherad av andra vägar som leder bort från huvudleden. I den konceptuella förändringen som mindfulness genomgått, tenderar mindfulness av sekulära och nyreligiösa uttolkare istället att förstås som en uppskattning av vad åkturen ger i form av de sinnesintryck landskapet skapar. Mindfulness har på så sätt kommit att signalera en förstärkning av inre upplevelser. Detta reflekterar en generell utveckling i västerländska länder där andlighet ersätter religion. När mindfulnessförespråkare explicit refererar till att tekniken är hämtad från buddhistisk tradition, förstås buddhism som ett alternativ till religion. Emellertid tas liten hänsyn till hur sati begreppsliggörs i buddhistisk tradition, och det uppstår begreppsliga sammanblandningar när termen mindfulness används utanför dess religiösa sammanhang. Kanske skulle ett annat språkbruk underlätta och tydliggöra vad den meditativa träningen till stor del tycks handla om i terapeutiska och kommersiella sammanhang: uppmärksamhet, rätt och slätt.

\section{LITTERATUR}

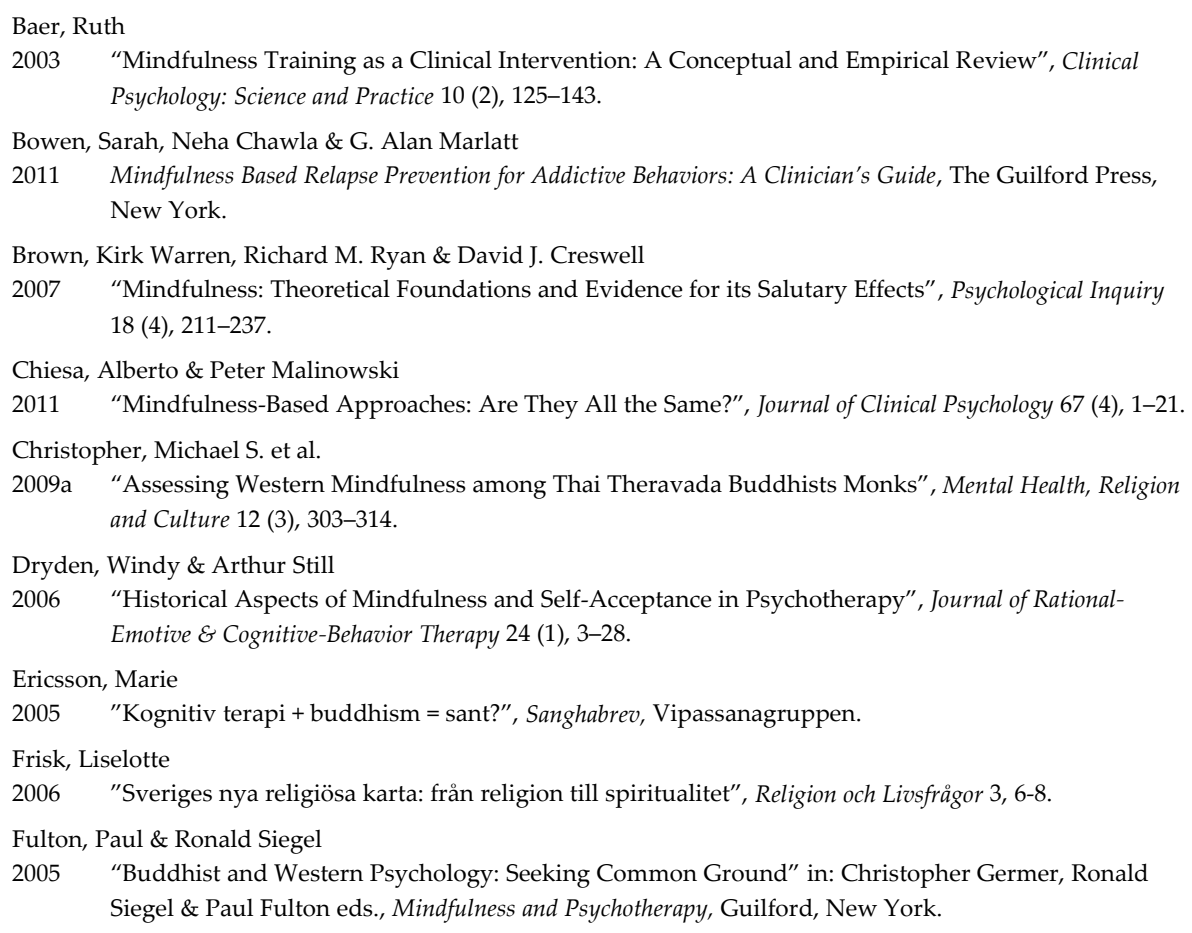


Germer, Christopher

2005 "Mindfulness - What Is It? Why Does It Matter?" in: Christopher Germer, Ronald Siegel \& Paul Fulton, eds., Mindfulness and Psychotherapy, Guilford, New York.

Gilpin, Richard

2008 "The Use of Theravada Buddhist Practices and Perspectives in Mindfulness-based Cognitive Therapy", Contemporary Buddhism - an Interdisciplinary Journal 9 (2), 227-251.

Heelas, Paul

1996a “Introduction: Detraditionalization and its Rivals" in: Paul Heelas et al., eds., Detraditionalization: Critical Reflections on Authority and Identity, Blackwell Publishers, Malden, MA.

Hornborg, Anne-Christine

2010a "Att sälja natur och hälsa: om rituellt helande i det senmoderna Sverige" in: Anne-Christine Hornborg, ed., Den rituella människan - flervetenskapliga perspektiv, Linköping University Electronic Press.

2010b "Designing Rites to Re-enchant Secularized Society: New Varieties of Spiritualized Therapy in Contemporary Sweden", The Journal of Religion and Health [on-line 25 maj 2010].

2012 Coaching och lekmannaterapi - en modern väckelse?, Dialogos Förlag, Stockholm.

Jacobsen, Knut

2002 Buddhismen - Religion, historia, liv, Natur och Kultur, Stockholm.

Johansson, Rune E. A.

1983 Dhammapada - buddhistiska aforismer, Natur och Kultur, Stockholm.

Kabat Zinn, Jon

2005 Vart du än går är du där - medveten närvaro i vardagen, Natur och Kultur, Stockholm [1994].

Lasch-Quinn, E

2004 "Liberation Therapeutics: From Moral Renewal to Consciousness-Raising", in: Jonathan Imber, ed. Therapeutic Culture - Triumph and Defeat, Transaction Publishers, Piscataway, New Jersey.

Kåver, Anna

2004 Att leva ett liv, inte vinna ett krig: om acceptans, Natur och Kultur, Stockholm.

Lopez, Donald

2008 Buddhism and Science: A Guide for the Perplexed, University of Chicago Press, Chicago.

McMahan, David

2008 The Making of Buddhist Modernity, Oxford University Press, Oxford.

Nilsonne, Åsa

2004 Vem är det som bestämmer i ditt liv? Om medveten närvaro, Natur och Kultur, Stockholm

Nyanatiloka Thera

1997 Buddhist Dictionary, BPS, Kandy [1952].

Olendzki, Andrew

2005 "The Roots of Mindfulness" in: Christopher Germer, Ronald Siegel \& Paul Fulton, eds., Mindfulness and Psychotherapy, Guilford, New York.

Plank, Katarina

2009 "Buddhister och Buddhism" in: Daniel Andersson \& Åke Sander, eds., Det mångreligiösa Sverige - ett landskap i förändring, Studentlitteratur, Lund, 221-284.

2010 "Mindful Medicine: The Growing Trend of Mindfulness-Based Therapies in the Swedish Health Care System", Finnish Journal of Ethnicity and Migration 5 (2), 47-55.

2011 Insikt och närvaro - Akademiska kontemplationer kring buddhism, meditation och mindfulness, Makadam Förlag, Göteborg.

Rapgay, Lobsang \& Bystrisky, Alexander

2009 "Classical Mindfulness - An Introduction to Its Theory and Practice for Clinical Application", Longevity, Regeneration, and Optimal Health: Annals of the New York Academy of Science, 1172, 148-162. 
Schenström, Ola

2007 Mindfulness i vardagen: Vägar till medveten närvaro, Bokförlaget Forum, Stockholm.

Thanissaro Bhikkhu

2010a "Mahasatipatthana Sutta: The Great Frames of Reference", Access to Insight [www. accesstoinsight.org]

Thanissaro Bhikkhu

2010b "Mindfulness Defined", Access to Insight [www.accesstoinsight.org].

Walsh, Roger \& Shapiro, Shauna

2006 "The Meeting of Meditative Disciplines and Western Psychology - A Mutually Enriching Dialogue", American Psychologist 61 (3), 227-239.

Åkerlund, Robin

2004 "Buddhism som färdighet", Chakra - tidskrift för indiska religioner 2, 47-57.

Katarina Plank, fil dr Institutionen för litteratur, idéhistoria och religion, Göteborgs universitet 